\title{
Decreasing incidence of adenotonsillar problems in Dutch general practice: real or artefact?
}

\author{
Marion CJ Biermans, Ellen HM Theuns-Lamers, Peter Spreeuwenberg, Robert A Verheij, \\ Johannes $C$ van der Wouden, Pieter F de Vries Robbé and Gerhard A Zielhuis
}

\section{ABSTRACT}

Background

The incidence of hypertrophy and recurrent infections of the tonsils/adenoids appears to be decreasing in the Netherlands. It is uncertain whether this is a 'real' decrease in the incidence of disease or an 'artefact'. Aim

To investigate possible causes of the decreasing incidence of adenotonsillar problems among Dutch children.

Design of study

Observational.

Setting

A nationally representative general practice database. Method

Incidence rates were calculated over 2002-2005 among children aged 0-14 years. Multilevel Poisson regression analyses were used to examine the following possible causes of changing incidence rates: change in recording (more substitution codes), change in the demand for care (fewer visits to the GP), and change in the supply of care (fewer antibiotic prescriptions and referrals). Indications for a 'real' change in the incidence of disease were examined by calculating incidence rates of other clinical

manifestations of microbial pathogens that may cause adenotonsillar problems.

Results

The incidence rate decreased significantly $(P=0.017)$ from 3.0 to 1.3 per 1000 children per year. Correcting for demand for and supply of care led to a smaller decline in yearly incidence, from 2.9 to 1.7 per 1000 children per year $(P=0.105)$. No clearly similar trend was found in other clinical manifestations of viruses and bacteria that may cause adenotonsillar problems. Conclusion

Part of the declining trend can be explained by a change in the demand for and supply of care, but no apparent causal clue emerged for the residual declining trend in the incidence of disease.

Keywords

adenoids; child; family practice; incidence; microbiology; tonsillitis.

\section{INTRODUCTION}

Adenotonsillar problems, notably obstructive hypertrophy and infection, are very common in early childhood and an important reason for parents to visit the GP with their child. Recurrent infections of the tonsils/adenoids can be a source of both upper and lower respiratory tract infections. Hypertrophy can lead to sleep-disordered breathing, eating disorders, and even growth problems..$^{1-5}$

The relationship between hypertrophy and recurrent infections of adenotonsillar tissue is unclear. Although hypertrophy is associated with recurrent infections of adenotonsillar tissue, many children present hypertrophy in the absence of infection. ${ }^{1,6-8}$ Some suggest that the tonsils and adenoids may only appear to be large due to their

MCJ Biermans, MA, MSc, epidemiologist; PF de Vries Robbé, $M D, P h D$, professor of medical informatics, Department of

Medical Informatics; GA Zielhuis, PhD, professor of epidemiology, Department of Epidemiology, Biostatistics and Health Technology Assessment, Radboud University Nijmegen Medical Centre, Nijmegen, the Netherlands. P Spreeuwenberg. $M S c$, statistician; RA Verheij, $P h D$, research coordinator, Netherlands Information Network of General Practice, Netherlands Institute for Health Services Research, Utrecht, the Netherlands. EHM Theuns-Lamers, MD, GP trainee; JC van der Wouden, PhD, senior lecturer, Department of General Practice, University Medical Center Rotterdam, Rotterdam, the Netherlands.

Address for correspondence

MCJ Biermans, Department of Medical Informatics, Radboud University Nijmegen Medical Centre, 152 MI, PO Box 9101, 6500 HB Nijmegen, The Netherlands. E-mail: m.biermans@elg.umcn.nl

Submitted: 20 April 2009; Editor's response: 26 May 2009; final acceptance: 27 May 2009.

(OBritish Journal of General Practice

This is the full-length article of an abridged version published in print. Cite this article as: Br J Gen Pract 2009; DOI: 10.3399/bjgp09X473141. 
prominence or relative size in the throat during childhood. $^{7}$ Recent magnetic resonance imaging studies, however, indicate that the tonsils and adenoids grow proportionally to the skeletal structures during normal child development., ${ }^{9,10}$

Treatment options for adenotonsillar problems in general practice include watchful waiting, symptomatic medication, antibiotics, or referral to an otorhinolaryngologist. Recurrent tonsillitis, as well as obstructive sleep apnoea due to adenotonsillar hypertrophy, are important indications for (adeno)tonsillectomy, a common surgical procedure on children. There is an ongoing debate about the proper indications for (adeno)tonsillectomy, resulting in widely varying surgical rates. ${ }^{11}$

The few studies that examined the incidence of this health problem in general practice indicate, at least for the Netherlands, that the incidence of hypertrophy and recurrent infections of the tonsils/adenoids among the total population is decreasing. ${ }^{12,13}$ Studies that examined acute tonsillitis in general practice found decreasing overall consultation rates in the UK (1994-2000) ${ }^{14}$ and in Sweden (1999-2005). ${ }^{15} \quad$ Considering these decreasing rates, the question arises whether there is a 'real' decrease in the incidence of hypertrophy and recurrent infections of the tonsils/adenoids, or whether it is an 'artefact' originated by other causes than the incidence of disease.

In an earlier paper by the current authors, four categories of possible causes of changing incidence rates in general practice were outlined: changes in recording, changes in the demand for care, changes in the supply of care, and 'real' changes in the incidence of a disease. ${ }^{13}$ Based on this categorisation, the following hypotheses were put forward.

\section{Changes in recording}

A shift in recording might explain the decrease in hypertrophy and recurrent infections of the tonsils/adenoids. GPs might have replaced the diagnostic code for this particular health problem with other codes.

\section{Changes in the demand for care}

The overall consultation frequency of Dutch children aged 0-14 years decreased from 1987 to $2001 .{ }^{16}$ This trend may have continued and may explain the decrease in adenotonsillar problems.

\section{Changes in the supply of care}

Dutch GPs usually work according to guidelines. In 1999 the guideline 'Acute sore throat' was revised, advocating restraint in prescribing antibiotics. ${ }^{17}$ Recommendations for referring to an otorhinolaryngologist also changed, now requiring

\section{How this fits in}

A decreasing incidence of hypertrophy and recurrent infections of the

tonsils/adenoids has been reported in Dutch general practice. Opinions on the

diagnostics and treatment consequences of this health problem vary widely, which

raises the question of whether the decline reflects a 'real' decrease in the incidence

of disease or is merely an 'artefact'. This study found a decrease in the incidence

of hypertrophy and recurrent infections of the tonsils/adenoids among children

aged $0-14$ years in the Netherlands. Part of the declining trend can be explained

by a change in the demand for and supply of care. Although unmeasured factors

in demand or supply may further explain the decrease in adenotonsillar problems,

a 'real' decline in the incidence of disease cannot be ruled out.

four (instead of three) severe episodes of tonsillitis per year. ${ }^{17}$ These policy changes might have reduced the number of consultations for this specific health problem. The fewer children who are treated with antibiotics or (adeno)tonsillectomy, the less parents are inclined to visit the GP with their child for these treatments.

\section{Changes in the incidence of a disease}

Viruses and bacteria are important pathogens in the aetiology of hypertrophy and infections of the tonsils/adenoids. Viruses dominate in preschool children. ${ }^{18}$ Viral pathogens are: adenovirus, parainfluenza virus, respiratory syncytial virus, rhinovirus, Epstein-Barr virus, and herpes simplex virus. Bacterial species that have been isolated are: Haemophilus influenzae, Streptococcus pyogenes, Streptococcus pneumonia, and Staphylococcus aureus. ${ }^{18-30}$ A decrease in the incidence of these pathogens could explain a decrease in adenotonsillar problems. The present study uses a national general practice database to explore the trend in the incidence of hypertrophy and recurrent infections of the tonsils/adenoids, and the causes of any changes identified, among children aged 0-14 years in the Netherlands.

\section{METHOD}

\section{Data set}

Data were used from the electronic medical records of Dutch general practices participating in the Netherlands Information Network of General Practice (LINH) during 2002-2005. ${ }^{31,32}$ GPs within this network code consultations, prescriptions, and referrals on a routine basis using the International Classification of Primary Care (ICPC). ${ }^{33}$ All ICPC codes were grouped into episodes, either by EPICON (a new record linkage method for contact-oriented electronic medical records) or by GPs (for episode-oriented electronic medical records). ${ }^{34-36}$ Only practices that met predefined criteria for accuracy and 
completeness were included in the analyses; this resulted in 69 practices in 2002, 66 in 2003, 43 in 2004, and 42 in 2005. The included practices are considered representative for all Dutch practices regarding urbanisation, practice type (single-handed or group practice), and region. Further details on this dataset have been described elsewhere. ${ }^{13}$ For the current study, a subset was selected from the total dataset that includes only data from the population between 0 and 14 years of age. This subset was used for all analyses.

\section{Study population}

A total of 80836 patients (41512 males and 39324 females) aged 0-14 years was available for this analysis. Age was measured on 1 July in the year concerned. This population is representative for the equivalent Dutch population (aged 0-14 years) regarding age and sex. ${ }^{37}$

\section{Outcome}

The main outcome variable was the yearly incidence of hypertrophy and recurrent infections of the tonsils/adenoids (ICPC code R90). Generally, GPs use this code for recurrent tonsillitis (at least three incidences per year) or obstructive hypertrophy. The total number of patients aged 0-14 years with a new diagnosis of hypertrophy and recurrent infections of the tonsils/adenoids (R90) was 507 in 2002, 451 in 2003, 236 in 2004, and 202 in 2005.

Indications for a 'real' change in the incidence of disease were examined by estimating incidence rates of clusters of other diseases that share the same pathogens with adenotonsillar problems. These clusters were composed as follows:

- based on the literature, the major microbial pathogens of hypertrophy and infections of the tonsils/adenoids were listed; ${ }^{18-30}$

- next, other frequent clinical manifestations of these pathogens were looked for and the corresponding ICPC codes selected. Clinical manifestations involving a general ICPC code, such as coughing (R05), were excluded; and

- for each pathogen a cluster of ICPC codes was composed (Appendix 1).

\section{Explanatory variables}

Possible changes in recording were examined by composing a cluster of possible substitution codes for ICPC code R90 (Appendix 2). The overall consultation frequency was used as a measure for the demand for care, whereas changes in the supply of care were measured by referrals to an otorhinolaryngologist and prescriptions of antibiotics. Table 1 gives a detailed description of these explanatory variables.

\section{Incidence rates}

Raw and adjusted incidence rates were calculated. The raw rates were computed as the total number of new episodes of a (cluster of) health problem(s) divided by the mid-year population (that is, the average of the population aged $0-14$ years at the beginning and the end of a year, which is used as an estimate for the observed person-years at risk). The mid-year population was 54437 in 2002, 53238 in 2003, 32151 in 2004, and 30576 in 2005. The episodes were weighted for the recording period of each practice within each year to account for holidays, etcetera (198 of the 220 included practiceyears covered a complete year and 22 covered slightly less than a year).

Adjusted incidence rates were calculated to (a) correct for confounding, and (b) estimate the effect of the explanatory variables on the incidence rates. To correct for confounding, a basic model was designed that corrects for age, sex, length of recording, and clustering. (The correction for clustering is necessary from a statistical point of view; it means that the

Table 1. Explanatory variables.

\begin{tabular}{|c|c|c|}
\hline Variable & Description & Range \\
\hline $\begin{array}{l}\text { Raw incidence of substitution } \\
\text { cluster }\end{array}$ & $\begin{array}{l}\text { Total number of new episodes of substitution codes in } 1 \text { year } \\
\text { per patient divided by total mid-year population }\end{array}$ & $\begin{array}{l}288.12 \text { to } 364.78 \\
\text { (per } 1000 \text { children per year) }\end{array}$ \\
\hline Consultation frequency & $\begin{array}{l}\text { Total number of consultations }{ }^{a} \text { per practice per year divided by } \\
\text { practice mid-year population }\end{array}$ & $\begin{array}{l}0.54 \text { to } 3.68 \\
\text { (per child per practice per year) }\end{array}$ \\
\hline Referral frequency & $\begin{array}{l}\text { Total number of referrals to an otorhinolaryngologist for a a new episode } \\
\text { of 'hypertrophy/recurrent infections of tonsils/adenoids' per practice } \\
\text { per year divided by practice mid-year population }\end{array}$ & $\begin{array}{l}0.00 \text { to } 21.05 \\
\text { (per } 1000 \text { children per practice per year) }\end{array}$ \\
\hline Antibiotics frequency & $\begin{array}{l}\text { Total number of antibiotic prescriptions for a new episode of } \\
\text { 'hypertrophy/recurrent infections of tonsils/adenoids' per practice } \\
\text { per year divided by practice mid-year population }\end{array}$ & $\begin{array}{l}0.00 \text { to } 75.79 \\
\text { (per } 1000 \text { children per practice per year) }\end{array}$ \\
\hline
\end{tabular}

aGPs assigned an International Classification of Primary Care (ICPC) code to each problem presented during a consultation. Total number of consultations was measured as the total number of ICPC codes. 
incidence rates are corrected for the fact that repeated observations of a health problem are clustered within patients and within practices.) The basic model estimates the incidence for an 8-yearold patient (mean age of this health problem in the population) and has been described in detail elsewhere. ${ }^{13}$

To estimate the effect of each additional explanatory variable on the corrected incidence rates, the explanatory variables were entered stepwise into the basic model. Variables were only included if they (a) increased or decreased over time in the expected direction based on the raw analyses, and (b) were significantly associated with hypertrophy and recurrent infections of the tonsils/adenoids (according to the 95\% confidence intervals [Cls] of the rate ratio [RR]). For each of these models, a test was carried out for a linear trend over time. In the final model, the consultation, referral, and frequency of antibiotic prescriptions were added (in this order) to the basic model. Multilevel Poisson regression models (MLwiN 2.02) were used to estimate the adjusted incidence rates.

\section{RESULTS}

\section{Overall trend}

Figure 1 shows the annual adjusted incidence rates of hypertrophy and recurrent infections of the tonsils/adenoids among children aged 0-14 years. Between 2002 and 2005, this rate decreased from $2.96(95 \% \mathrm{Cl}=2.16$ to 4.07$)$ to $1.27(95 \% \mathrm{Cl}=0.67$ to 2.41$)$ per 1000 children per year. The decrease is significant for the total group of children $(P=0.017)$, and for males $(P=0.021)$ and females $(P=0.022)$ separately. Note that these rates were adjusted and scaled (that is, the age variables were centred at 8 years), and therefore different from raw rates.

\section{Raw rates}

The raw rates of consultations, referrals, and antibiotic prescribing declined over 2002-2005. For instance, the total annual consultation frequency decreased from 1.98 in 2002 to 1.79 in 2005. Instead of the hypothesised increase of substitution codes, a decrease was found in the incidence rate of the cluster of substitution codes. Even when a cluster of only upper respiratory codes was computed, a decrease was noticed (Figure 2). Based on these raw rates, it was possible to reject the hypothesis that the decrease was caused by a shift in recording. Therefore, this variable was not included in the multilevel Poisson regression analyses.

\section{Adjusted rates}

Table 2 shows the rate ratios for the other explanatory variables: consultation frequency,

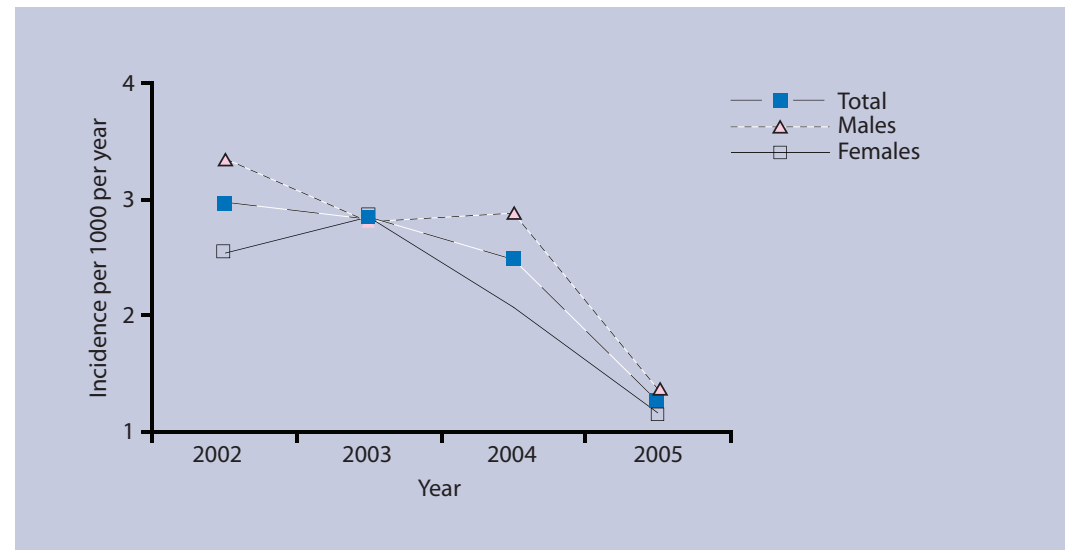

Figure 1. Adjusted incidence rates (basic model) of hypertrophy and recurrent infections of the tonsils/adenoids among children aged 0-14 years.

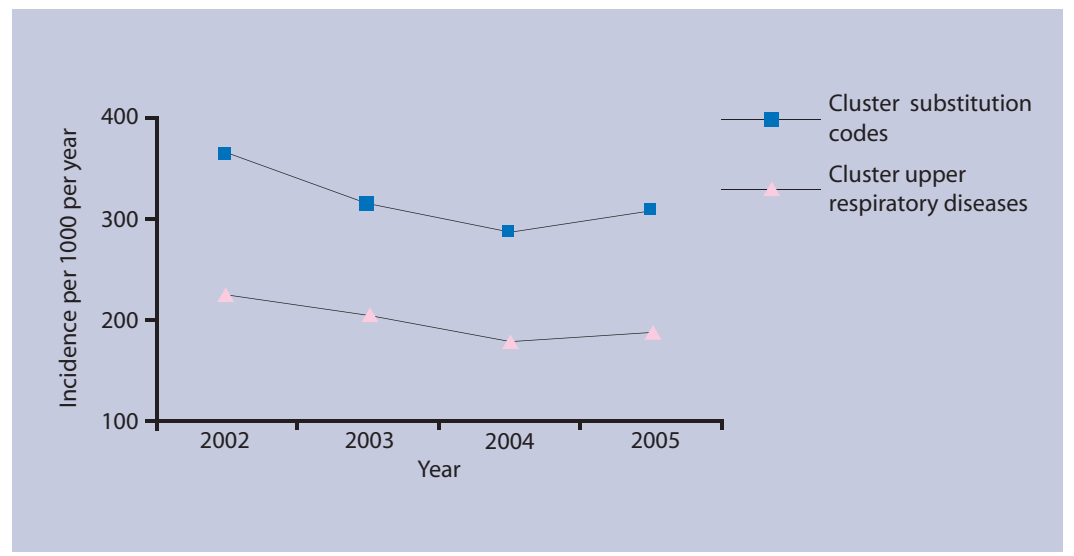

Figure 2. Raw incidence rates of clusters of substitution codes and upper respiratory diseases among children aged 0-14 years.

referral frequency, and antibiotics frequency. All associations are positive (that is, all rate ratios are larger than one), which means that an increase (or decrease) in one of the explanatory variables goes with an increase (or decrease) in the number of new episodes of hypertrophy and recurrent infections of the tonsils/adenoids over the examined 4-year period. These rate ratios can be interpreted in such a way that a mean decrease of one consultation per child per practice per year (for instance, when the consultations per child decrease from three to two per year) is associated with a $23 \%$ decrease in the risk of new episodes of hypertrophy and recurrent

\section{Table 2. Associations between the explanatory variables and new episodes of hypertrophy and recurrent infections of the tonsils/adenoids.}

\begin{tabular}{lcc} 
Variable & Rate ratio $^{\mathrm{a}}$ & $95 \% \mathrm{Cl}$ \\
\hline Consultation frequency & 1.23 & 1.02 to 1.48 \\
\hline Referral frequency & 1.09 & 1.07 to 1.12 \\
\hline Antibiotics frequency & 1.03 & 1.02 to 1.04 \\
\hline
\end{tabular}

a'Based on the final model. 


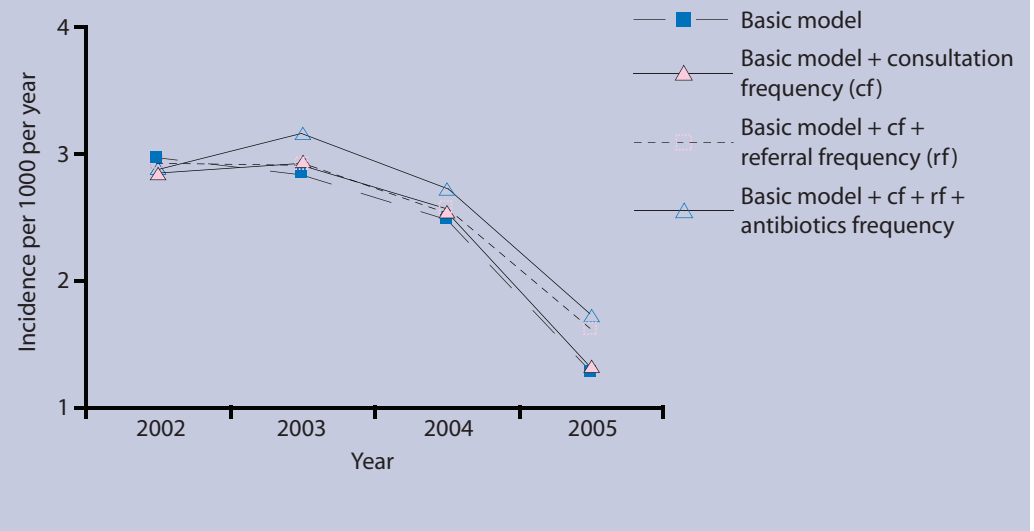

Figure 3. Adjusted incidence rates (various models) of hypertrophy and recurrent infections of tonsils/adenoids among children aged 0-14 years.

infections of the tonsils/adenoids over the examined 4-year period. All three variables are significantly associated with hypertrophy and recurrent infections of the tonsils/adenoids (that is, the 95\% Cls exclude 1).
Thus, these three variables have the potential to explain the decrease in adenotonsillar problems, because (a) they declined, and (b) they are associated with these problems. Figure 3 shows the impact of each of the variables on the adjusted incidence rate of hypertrophy and recurrent infections of the tonsils/adenoids. Each variable explains a small part of the decrease of this incidence rate. The linear trend over time was no longer significant after referral $(P=$ $0.075)$ and antibiotics frequency $(P=0.105)$ were entered into the model.

Figure 4. Adjusted incidence rates (basic model) among children aged 0-14 years of clusters of clinical manifestations of pathogens found in hypertrophy and recurrent infections of the tonsils/adenoids.

\section{Clinical manifestations of pathogens found in hypertrophy and infections of the tonsils/adenoids}

Figure 4 illustrates clusters of other clinical manifestations related to the same microbial pathogens held responsible for adenotonsillar

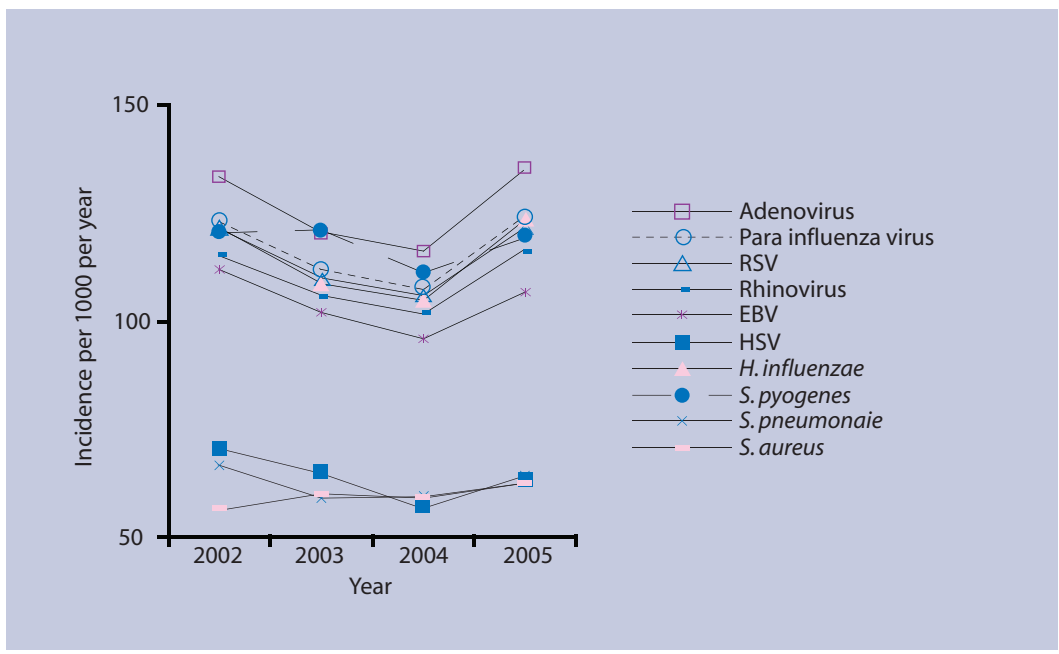

problems, which show no linear decrease over time. The shape of the trend over time corresponds to the trend observed in the cluster of respiratory diseases (Figure 2) and to the decline in adenotonsillar problems over the period of 2002-2004; whereas the rise of clinical manifestations in 2005 contrasts with the decrease in adenotonsillar problems in 2005 (Figure 3).

\section{DISCUSSION}

\section{Summary of main findings}

The incidence of recurrent infections and hypertrophy of the tonsils/adenoids among Dutch children decreased over the years 2002-2005. Part of the decline can be explained by changes in the demand for and supply of care during this period, whereas no indication was found for a change in recording. No clear indication was found for a 'real' change in the incidence of disease.

\section{Strengths and limitations of the study}

This study illustrates the potential use of data derived from electronic medical records in general practice. A large network of general practices, and therefore a large number of patients, were included in the analyses. The study population was representative of the Dutch population regarding age and sex. Furthermore, the database enabled study of the most obvious hypotheses for the observed decrease in adenotonsillar problems. A relatively new approach was used to analyse the data. Both the multilevel analyses and the composition of clusters of clinical manifestations of pathogens are applicable to other registries.

The study was limited, however, to the available evidence in the database. Hence, the decrease might be explained by other factors that were not measured in this study, such as changes in day care attendance. Furthermore, the study was limited to a 4-year period, whereas changes that occurred before this time frame may have caused the decrease. In particular, the large decrease in (adeno)tonsillectomy rates during the 1970s and 1980s in the Netherlands ${ }^{11}$ may have caused a general decrease in attention for adenotonsillar problems among parents, GPs, and otorhinolaryngologists. This historical change in supply may still have a lingering effect on the current incidence rates.

Furthermore, the change in actual pathogens that cause the disease was not measured. Instead, a proxy was used consisting of clusters of clinical manifestations of pathogens found in hypertrophy and infections of the tonsils/adenoids, which has several disadvantages. First, it is not possible to be certain that the identified viruses and bacteria actually cause adenotonsillar problems, because the presence of an 
organism in a patient's throat and its culture from a swab does not mean that it is pathogenic. ${ }^{5}$ Second, other microbial pathogens may also cause the clinical manifestations that were used in this study. In particular, some of the clinical manifestations could be caused by influenza viruses. Within the ICPC, a separate code is used for (proven) influenza (R80). Probably, GPs use some of the codes that are included in the clinical manifestations to record influenza-like-illness (which can be caused by many viruses, including influenza viruses, rhinovirus, and respiratory syncytial virus). ${ }^{38,39}$ In 2003 , there were two influenza epidemics, the first one started in February, and the second one in November. ${ }^{40}$ The latter has probably led to higher rates of influenza-like illness in 2003, and lower rates in 2004, which might explain a small part of the decrease of clinical manifestations in 2004. This reasoning exemplifies that the incidence rates of the clusters of clinical manifestations should be interpreted cautiously; they only give an indication and cannot provide any evidence of a change in the incidence of major pathogens held responsible for adenotonsillar problems.

Finally, not all referrals and prescriptions were linked to an ICPC code by the GPs. Each year, ICPC codes were missing for $3-5 \%$ of the referrals to otorhinolaryngologists and for $7-10 \%$ of the antibiotic prescriptions. Therefore, the referral and antibiotics frequency might have been underestimated, but there is no reason to believe that higher estimates would have changed the conclusions from this study.

\section{Comparison with existing literature}

The findings of this study raise the question of whether the decrease of adenotonsillar problems is related to an overall decline in upper respiratory tract diseases. Both adenotonsillar problems and other upper respiratory tract diseases declined over 2002-2004, whereas opposite trends were observed over 2005. The opposite trend is over 1 year only; a longer period of observation is needed to reveal whether adenotonsillar problems show patterns over time that are generally similar to upper respiratory tract infections.

Over the last decade, decreasing consultation rates of various respiratory tract infections in general practice have been reported in the Netherlands, the UK, Sweden, and the US. 14,15,41-45 Reductions in antibiotics prescriptions account only partly for this decline, because the decrease in antibiotic prescribing for patients presenting with a respiratory tract infection is much smaller than the decrease in consultation rates. ${ }^{14,15,41,42,45}$ Thus, the question why patients present less frequently with respiratory tract infections remains largely unanswered. Some suggest that this decline is caused by a reduced inclination of patients to present respiratory illness to their $\mathrm{GP}^{14,42}$ whereas others suggest a 'real' decrease in the incidence of respiratory tract infections. ${ }^{44}$ The results of the present study appear to be in favour of the last hypothesis, because the decrease in the overall consultation frequency had only little impact on the observed decline in adenotonsillar problems (Figure 3). The basic model, however, controls for clustering within practices, which may already reduce some of the variance caused by differences in consultation frequency.

Furthermore, the study controlled for the total consultation frequency among children, while the decline could be respiratory specific (that is, parents are only less inclined to visit the GP with their child for respiratory problems). Hence, the actual impact of consultation frequency might be somewhat larger. Nevertheless, the present findings demonstrate that consultation frequency provides no conclusive explanation for the decline in adenotonsillar problems.

In the present study, a decline was observed in both the antibiotics and the referral frequency for hypertrophy and recurrent infections of the tonsils/adenoids among children over the years 2002-2005. This finding corresponds with declining antibiotic prescribing trends for acute tonsillitis, and with decreasing referral rates for hypertrophy and recurrent infections of the tonsils/adenoids among Dutch children during 1987 to $2001 . .^{41,46}$

\section{Implications for clinical practice and future research}

A substantial decline in adenotonsillar problems was observed among children over 2002-2005, partly explained by factors that are not causally linked to the aetiology of the disease itself. For the residual decline, no apparent causal clue has yet emerged. It is therefore premature to formulate implications for GPs or otorhinolaryngologists. More research is needed to assess causes for the residual, unexplained decline currently escaping attention. In particular, future research should focus on the question of whether the observed decrease is part of an overall decline in upper respiratory tract infections resulting from a changing pattern in the occurrence of major pathogens in the population. Further insight into this issue is especially important for planning healthcare services, because upper respiratory tract infections form a substantial part of the workload in general practice, ear, nose, and throat surgery, and paediatrics.

\section{Funding body}

This study was supported by ZonMw, the Netherlands organisation for health research and development, reference number 014-18-013

\section{Ethics committee}

Not applicable 


\section{Competing interests}

The authors have stated that there are none.

\section{Discuss this article}

Contribute and read comments about this article on the Discussion Forum: http://www.rcgp.org.uk/bjgp-discuss

\section{REFERENCES}

1. Kara CO, Ergin H, Kocak G, et al. Prevalence of tonsillar hypertrophy and associated oropharyngeal symptoms in primary school children in Denizli, Turkey. Int J Pediatr Otorhinolaryngol 2002; 66(2): 175-179.

2. Kvaerner KI, Tambs K, Harris JR, et al. Otitis media: relationship to tonsillitis, sinusitis and atopic diseases. Int J Pediatr Otorhinolaryngol 1996; 35(2): 127-141.

3. Bonuck K, Parikh S, Bassila M. Growth failure and sleep disordered breathing: a review of literature. Int J Pediatr Otorhinolaryngol 2006; 70(5): 769-778.

4. Tal A, Bar A, Leiberman A, et al. Sleep characteristics following adenotonsillectomy in children with obstructive sleep apnea syndrome. Chest 2003; 124(3): 948-953.

5. Cowan DL, Hibbert J. Acute and chronic infection of the pharynx and tonsils. In: Kerr AG, Hibbert J (eds). Scott-Brown's otolaryngology. Laryngology and head and neck surgery. 6th edn. Oxford: ButterworthHeinemann, 1997: 5/4/1-5/4/24

6. Potsic WP. Assessment and treatment of adenotonsillar hypertrophy in children. Am J Otolaryngol 1992; 13(5): 259-264.

7. Cable HR, Batch AG, Stevens DJ. The relevance of physical signs in recurrent tonsillitis in children. A prospective study. J Laryngol Otol 1986, 100(9): 1047-1051.

8. Barr GS, Crombie IK. Comparison of size of tonsils in children with recurrent tonsillitis and in controls. BMJ 1989; 298(6676): 804.

9. Arens R, McDonough JM, Corbin AM, et al. Linear dimensions of the upper airway structure during development. Am J Respir Crit Care Med 2002; 165(1): 117-122.

10. Vogler RC, Wippold FJ, Pilgram TK. Age-specific size of the normal adenoid pad on magnetic resonance imaging. Clin Otolaryngol 2000; 25(5): 392-395.

11. Van den Akker EH, Hoes AW, Burton MJ, et al. Large international differences in (adeno)tonsillectomy rates. Clin Otolaryngol 2004; 29(2): $161-164$.

12. Van de Lisdonk EH, van den Bosch WJHM, Lagro-Janssen ALM (eds), Ziekten in de huisartsenpraktijk. [Diseases in general practice]. Maarssen: Elsevier Gezondheidszorg, 2003: 209.

13. Biermans MCJ, Spreeuwenberg P, Verheij RA, et al. Striking trends in de incidence of health problems in the Netherlands (2002-05). Finding from a new strategy for surveillance in general practice. Eur J Public Health 2009; 19(3): 290-296.

14. Ashworth $\mathrm{M}$, Latinovic R, Charlton J, et al. Why has antibiotic prescribing for respiratory illness declined in primary care? A longitudinal study using the General Practice Research Database. J Public Health (Oxf) 2004; 26(3): 268-274.

15. Neumark T, Brudin L, Engström S, et al. Trends in number of consultations and antibiotic prescriptions for respiratory tract infections between 1999 and 2005 in primary healthcare in Kalmar County, Southern Sweden. Scand J Prim Health Care 2009; 27(1): 18-24.

16. Van den Berg MJ, Kolthof ED, De Bakker DH, et al. De werkbelasting van huisartsen. [The workload of general practitioners]. Utrecht: Nivel, 2004: 56-57.

17. Dagnelie CF, Zwart S, Balder FA, et al. NHG Standard 'Acute sore throat' from the Dutch College of General Practitioners, first revision, 1999. http://nhg.artsennet.nl/upload/104/guidelines2/E11.htm (accessed 25 Sept 2009).

18. Putto A. Febrile exudative tonsillitis: viral or streptococcal? Pediatrics 1987; 80(1): 6-12.

19. Tosca MA, Riccio AM, Marseglia GL, et al. Nasal endoscopy in asthmatic children: assessment of rhinosinusitis and adenoiditis incidence, correlations with cytology and microbiology. Clin Exp Allergy 2001; 31(4): 609-615.

20. Bisno AL. Acute pharyngitis. N Engl J Med 2001; 344(3): 205-211.

21. Suvilehto J, Roivainen M, Seppänen M, et al. Rhinovirus/enterovirus RNA in tonsillar tissue of children with tonsillar disease. J Clin Virol 2006; 35(3): 292-297.

22. Gaffney RJ, Timon CI, Freeman DF, et al. Bacteriology of tonsil and adenoid and sampling techniques of adenoidal bacteriology. Respir Med 1993; 87(4): 303-308

23. DeDio RM, Tom LWC, McGowan KL, et al. Microbiology of the tonsils and adenoids in a pediatric population. Arch Otolarynol Head Neck
Surg 1988; 114(7): 763-765

24. Van Staaij BK, Van den Akker EH, De Haas van Dorsser EHM, et al. Does the tonsillar surface flora differ in children with and without tonsillar disease? Acta Otolaryngol 2003; 123(7): 873-878.

25. Endo LH, Ferreira D, Montenegro MCS, et al. Detection of Epstein-Bar virus in tonsillar tissue of children and the relationship with recurrent tonsillitis. Int J Pediatr Otorhinolaryngol 2001; 58(1): 9-15.

26. Brook I. Aerobic and anaerobic bacteriology of adenoids in children: a comparison between patients with chronic adenotonsillitis and adenoid hypertrophy. Laryngoscope 1981; 91(3):377-382.

27. Gaffney RJ, Cafferkey MT. Bacteriology of normal and diseased tonsils assessed by fine needle aspiration: haemophilus influenzae and the pathogenesis of recurrent acute tonsillitis. Clin Otolaryngol 1998; 23(2): $181-185$.

28. Brook I, Yocum P, Foote PA. Changes in the core tonsillar bacteriology of recurrent tonsillitis: 1977-1993. Clin Infect Dis 1995; 21(1): 171-176.

29. Jeong JH, Lee DW, Ryu RA, et al. Bacteriologic comparison of tonsil core in recurrent tonsillitis and tonsillar hypertrophy. Laryngoscope 2007; 117(12): $1-6$

30. Stjernquist-Desatnik A, Prellner K, Schalén C. High recovery of Haemophilus influenzae and group A streptococci in recurrent tonsillar infection or hypertrophy as compared with normal tonsils. J Laryngol Otol 1991; 105(6): 439-441.

31. Verheij RA, Van Dijk CE, Abrahamse H, et al. Netherlands Information Network of General Practice. Facts and figures on Dutch GP care. Utrecht/Nijmegen: NIVEL/WOK. http://www.linh.nl (accessed 3 Oct 2009).

32. Tacken MAJB. Quality of preventive performance in general practice: the use of routinely collected data. PhD Dissertation. Nijmegen: Radboud University Nijmegen, 2005.

33. Lamberts $\mathrm{H}$, Woods $\mathrm{M}$ (eds). International Classification of Primary Care (ICPC). Oxford: Oxford University Press, 1987.

34. Biermans MCJ, De Bakker DH, Verheij RA, et al. Development of a casebased system for grouping diagnoses in general practice. Int $\mathrm{J} \mathrm{Med}$ Inform 2008; 77(7): 431-439.

35. Biermans MCJ, Verheij RA, De Bakker DH, et al. Estimating morbidity rates from electronic medical records in general practice. Evaluation of a grouping system. Methods Inf Med 2008; 47(2): 98-106.

36. Biermans MCJ, Elbers GH, Verheij RA, et al. External validation of EPICON: a grouping system for estimating morbidity rates using electronic medical records. J Am Med Inform Assoc 2008; 15(6): 770-775.

37. Statistics Netherlands. StatLine database. http://statline.cbs.nl/StatWeb/?LA=en (accessed 16 Oct 2009).

38. Bellei N, Carraro E, Perosa A, et al. Acute respiratory infection and influenza-like illness viral etiologies in Brazilian adults. J Med Virol 2008 80(10): 1824-1827.

39. Meerhof TJ, Fleming D, Smith A, et al. Surveillance recommendation based on an exploratory analysis of respiratory syncytial virus reports derived from the European Influenza Surveillance System. BMC Infect Dis 2006; 6: 128.

40. European Centre for Disease Prevention and Control. Description of the European Influenza Surveillance Network (EISN) http://ecdc.europa.eu/en/activities/surveillance/EISN/Pages/AbouttheNet work Description.aspx (accessed 16 Oct 2009).

41. Diepenhorst HIJ, Otters HBM, Van Suijlekom-Smit LWA, et al. Tonsilliti acuta bij kinderen in de huisartsenpraktijk: verandering van incidentie en beleid? [Acute tonsillitis in children in the GP's practice: changes in incidence and policy?]. Huisarts Wet 2004; 47: 399-404.

42. Kuyvenhoven M, Van Essen G, Schellevis F, et al. Management of upper respiratory tract infections in Dutch general practice: antibiotic prescribing rates and incidences in 1987 and 2001. Fam Pract 2006; 23(2): 175-179.

43. Gommer AM, Poos MJJC. Neemt het aantal mensen met infecties van de bovenste luchtwegen toe of af? [Is the number of people with upper respiratory tract infections increasing or decreasing?]. http://www.rivm.nl/vtv/object_document/o1838n18079.html (accessed 25 Sept 2009).

44. Fleming DM, Ross AM, Cross KW, et al. The reducing incidence of respiratory tract infection and its relation to antibiotic prescribing. $\mathrm{BrJ}$ Gen Pract 2003; 53(495): 778-783.

45. McCaig LF, Besser RE, Hughes JM. Trends in antimicrobial prescribing rates for children and adolescents. JAMA 2002; 287(23):3096-3102.

46. Otters H, Van der Wouden JC, Schellevis FG, et al. Dutch general practitioners' referral of children to specialists: a comparison between 1987 and 2001. Br J Gen Pract 2004; 54(508): 848-852. 


\section{Online Appendix 1. Clusters of other clinical manifestations (and corresponding ICPC codes) of pathogens found in hypertrophy and recurrent infections of the tonsils/adenoids.}

- Adenovirus: coryza (R74), otitis media (H71-H72), bronchitis (R78), pneumonia (R81), diarrhoea (D73), pharyngitis (R74) conjunctivitis (F70), tonsillitis (R22/R76)

- Parainfluenza virus: laryngotracheobronchitis (R77), pneumonia (R81), bronchiolitis (R78), otitis media (H71-H72), sinusitis (R75), upper respiratory tract infection (R74), tonsillitis (R22/R76)

- Respiratory syncytial virus: bronchiolitis (R78), pneumonia (R81), coryza (R74), sinusitis (R75), otitis media (H71-H72), tonsillitis (R22/R76)

- Rhinovirus: coryza (R74), acute sinusitis (R75), otitis media (H71-H72), pharyngitis (R74), bronchitis (R78), asthma attack (R96), tonsillitis (R22/R76)

- Epstein-Barr virus: otitis media (H71-H72), diarrhoea (D73), upper respiratory tract infection (R74), infectious mononucleosis (A75), pneumonia (R81), tonsillitis (R22/R76)

- Herpes simplex virus: gingivostomatitis (D82), oral lesions (S71), keratitis (F73), conjunctivitis (F70), blepharitis (F72), laryngitis (R77), tonsillitis (R22/R76)

- Haemophilus influenza: acute sinusitis (R75), otitis media (H71-H72), acute conjunctivitis (F70), exacerbation chronic bronchitis (R78), pneumonia (R81), meningitis (N71), epiglottis (R77), septic artritis (L70), osteomyelitis (L70), cellulitis (S10), tonsillitis (R22/R76)

- Streptococcus pyogenes: sinusitis (R75), cellulitis (S10), otitis media (H71-H72), acute rheuma (K71), acute glomerulonefritis (U88), impetigo (S84), cellulitis (S10), meningitis (N71) tonsillitis (R22/R72)

- Streptococcus pneumoniae: pneumonia (R81), meningitis (N71), sinusitis (R75), otitis media (H71-H72), tonsillitis ( R22/R76)

- Staphylococcus aureus: furunkel (S10), impetigo (S84), pneumonia (R81), folliculitis (S11), tonsillitis (R22/R76)

ICPC = International Classification of Primary Care.
Online Appendix 2. Clusters of possible substitution codes for hypertrophy and recurrent infections of the tonsils/adenoids (R90).

- R01: pain attributed to respiratory system

- R04: other breathing problems

- R05: cough

- R07: sneezing/nasal congestion

- R08: other symptoms of nose

- R09: symptoms/complaints sinus

- R21: symptoms/complaints throat

- R22: symptoms/complaints tonsils

- R29: other symptoms respiratory system

- R72: strep throat/scarlet fever ${ }^{a}$

- R74: upper respiratory tract infection (head cold $)^{2}$

- R75: sinusitis acute/chronic ${ }^{a}$

- R76: tonsillitis acute

- R83: other infections respiratory system

- R97: hayfever, allergic rhinitis

- R99: other disease respiratory system

- A01: pain generalised/unspecified

- A02: chills

- A03: fever

- A75: infectious mononucleosis

- A77: other viral diseases

- A78: other infectious diseases

- H71: acute otitis media/myringitis ${ }^{\mathrm{a}}$

- H72: serious otitis media, glue ear

- H74: chronic otitis media, other infections of ear ${ }^{\mathrm{a}}$ ${ }^{a}$ Codes included in the upper respiratory cluster in Figure 2. 